\title{
STRATEGIC DECISION COMPREHENSIVENESS AND NEW PRODUCT DEVELOPMENT OUTCOMES IN NEW TECHNOLOGY VENTURES
}

\author{
KWAKU ATUAHENE-GIMA \\ City University of Hong Kong \\ HAIYANG LI \\ Texas A\&M University
}

\begin{abstract}
With a sample of new technology ventures in China, we investigated the contingent effect of strategic decision comprehensiveness on new product performance and product quality. The relationship between strategic decision comprehensiveness and new product performance was negatively moderated by technology uncertainty but positively moderated by demand uncertainty. The effect of decision comprehensiveness on new product quality was positively moderated by demand uncertainty but unaffected by technology uncertainty. The comprehensiveness-performance link emerges as more complex than previous research has shown.
\end{abstract}

A key distinguishing characteristic of the strategic management discipline is the emphasis it places on firms' competitive environments. Firms are viewed as information-processing or interpretation systems that scan and collect data from their environments, interpret the data, and then learn by acting upon the interpretation (Daft \& Weick, 1984). This notion is central to the contingency perspective that underlies information processing theory. According to the contingency perspective, the fit between the information-processing requirements facing a firm and the information-processing capacity offered by the firm's strategy process determines success (Galbraith, 1973; Tushman \& Nadler, 1978). For example, a key prediction of this theory is that in highly turbulent environments a firm faces complex information-processing requirements that are such that it requires organizational designs (including strategic processes, control systems, and communication patterns and structures) allowing realtime, fast information collection and interpretation (Daft \& Macintosh, 1981; Eisenhardt, 1989; Galbraith, 1973; Tushman \& Nadler, 1978).

Prior research has investigated this tenet within the domain of strategic decision comprehensiveness, which can be defined as the extent to which

We thank Don Bergh and our three $A M J$ reviewers for their support and constructive comments on earlier versions of this work, which also benefited from the comments and suggestions of James Robins, Jialin Xie, and Yan Zhang. We thank Guoqing Guo and Victor Li for assistance in data collection. The work described in this paper was fully supported by a grant from the Research Grants Council of the Hong Kong Special Administrative Region, China (project number CityU 1188/01/H). an organization attempts to be exhaustive and inclusive in making and integrating strategic decisions (Fredrickson, 1984; Fredrickson \& Mitchell, 1984; Lindblom, 1959). However, the results of empirical tests have been decidedly mixed. Some studies have shown that decision comprehensiveness enhanced firm performance in stable environments but diminished performance in unstable environments (Fredrickson, 1984; Fredrickson \& Mitchell, 1984). However, others have shown exactly the opposite (e.g., Goll \& Rasheed, 1997; Priem, Rasheed, \& Kotulic, 1995). Thus, it appears that the central tenet of information processing theory remains unproven. The mixed findings may stem from two causes. First, previous studies have used the firm as a unit of analysis, ignoring two potential confounds: the large array of factors that affect firm performance may mask the effect of a specific decision process (Dean \& Sharfman, 1996: 371 ), and managers may use different decision processes in different projects or even within single projects (Hough \& White, 2003). Second, prior research has tended to examine environmental uncertainty as a unidimensional construct, thereby ignoring the variety of demonstrated sources of uncertainty and different managerial interpretations of their effects.

Focusing on a single new product project in this study, we add to the body of knowledge through investigating a contingency model that explicitly considers the influence of technology and demand sources of uncertainty. Technology uncertainty refers to the perceived speed of change and unpredictability of technology in a firm's principal industry. It is characterized by short product development cycles and fast technological obsolescence. 
Demand uncertainty refers to the perceived speed of change and unpredictability of customers' product preferences and demands as well as the emergence of new customer segments (Jaworski \& Kohli, 1993). Our focus on perceived rather than objective environment reflects Weick's (1969) argument that the salient features of an environment are only those that are "enacted" by the perceptions of decision makers. Drawing on this interpretive view of strategic decision making (Daft \& Weick, 1984), we contend that managers perceive different information-processing demands from technology and demand uncertainties and that these differences determine the appropriateness and efficacy of strategic decision comprehensiveness. We advance extant literature by presenting the results of tests of whether this more elaborate representation of environmental uncertainty provides a better explanation of the strategic decision comprehensivenessperformance relationship.

However, even this model may be too limited in explaining the importance of strategic decision comprehensiveness in firm performance. Limitations arise because, like prior research, our model implies that market performance is the only desired goal in strategic decision making. This narrow focus limits theoretical completeness because there are other equally important goals, such as product quality and development speed, that firms seek from comprehensive strategy making (Eisenhardt, 1989). By failing to address such goals, previous research has provided little insight into the question of whether the type of goals pursued matters for strategic decision comprehensiveness under different environmental conditions. Rajagopalan, Rasheed, and Datta (1993: 351) alluded to this omission when they argued that to provide a fuller understanding of its role in organizational performance, a model of the strategic decision making process must recognize multiple outcomes simultaneously. We addressed this omission in the current study by examining new product quality as an additional outcome of strategic decision comprehensiveness. New product quality refers to the perceived superiority of a new product in terms of its reliability and customer satisfaction compared with other alternatives. New product quality was particularly important to examine here because scholars have argued that it is a key outcome of the strategic decision making process and perhaps the most important driver of a new product's market performance (Brown \& Eisenhardt, 1995).

In summary, we advance information processing theory by showing how a fit between strategic decision comprehensiveness and the different information-processing tasks associated with technology and demand sources of uncertainty influence both new product quality and market performance. Through this richer explanation and empirical assessment, we attempt to contribute to greater clarity and better understanding of how managers make organizational strategic decisions in response to environmental uncertainty.

\section{THEORETICAL BACKGROUND AND RESEARCH HYPOTHESES}

The effect of a firm's strategy on performance depends on the information-processing requirements created by the environmental factors it chooses to deal with (Galbraith, 1973). The strategic management literature suggests that firms deal with information-processing requirements through two models of strategic decision making: the incremental and the synoptic. An incremental decisionmaking process is a remedial response to current problems or dissatisfaction with a current state; in an incremental process, decision makers consider few alternatives and view strategy as loosely coupled decisions. It is a process of adaptation in the light of experience and therefore unfolds in small, incremental, tentative steps as a pattern of order emerges. The logic for incrementalism is that no single analytical process can handle all strategic variables and their interactions simultaneously on a planned basis (Braybrooke \& Lindblom, 1963; Quinn, 1980). In contrast, in the synoptic model, strategic decision making is viewed as a rational, comprehensive process that decision makers initiate in response to current problems and also to future opportunities. In this study, we defined decision comprehensiveness as the extent to which a project team is exhaustive and inclusive in making and integrating strategic decisions in developing a new product. It captures the extent to which the project team searches for information with a wide lens and considers multiple approaches, multiple courses of action, and multiple decision criteria in evaluating and selecting alternative courses of action (Fredrickson \& Mitchell, 1984; Miller, Burke, \& Glick, 1998).

Strategic decision comprehensiveness is generally argued to enhance performance because it allows decision makers to develop greater insights into their environment and become more realistic and effective in their assessments of that environment's potential impact on their organization, thereby ensuring effective decision making (Sniezek, 1992: 133). As mentioned earlier, however, empirical tests have yielded mixed results about the moderating role of environmental uncertainty. Fredrickson (1984) and Fredrickson and Mitchell (1984) found that strategic decision com- 
prehensiveness enhanced performance in stable environments but diminished firm performance in unstable environments because comprehensiveness did not allow quick enough adaptation to highly uncertain environments. In uncertain environments, comprehensiveness slowed the pace of decision making, hindered real-time information flow, and taxed both the financial and managerial resources of firms. Further, the cognitive limitations and bounded rationality of decision makers made it nearly impossible for them to account for every relevant problem, all environmental factors, and variation effects among those factors, as assumed under the synoptic model (Braybrooke \& Lindblom, 1963). In contrast, other studies have shown that strategic decision comprehensiveness enhanced performance in dynamic environments but diminished performance in stable environments (e.g., Goll \& Rasheed, 1997; Priem et al., 1995). For example, Bourgeois and Eisenhardt (1988) found that greater decision effectiveness in high-velocity environments was best accomplished by employing a rational comprehensive approach.

Although these studies have made valuable contributions, the focus on environmental uncertainty as a unidimensional construct is incomplete. This is because a simple categorization of environmental uncertainty into high and low categories, without attention to the sources of the uncertainty, can obscure some complex and contradictory effects of strategic decision comprehensiveness. The proponents of interpretive models of strategic decision making (Daft \& Macintosh, 1981; Daft \& Weick, 1984; Weick, 1969) have argued that managers are information processors and that a key factor in the effectiveness of strategic actions made in response to environmental uncertainty is managerial interpretation of the cause and effect relationships. A rational, comprehensive decision-making process is thought to be more effective where managers perceive their environment as analyzable and correct responses can be identified (Daft \& Weick, 1984). Therefore, we contend that making sense of the incongruity of prior empirical findings regarding the relationship between comprehensiveness and performance may hinge on examining the different moderating effects of sources of environmental uncertainty. In this study, we argue that technology and demand uncertainties have different moderating effects on the effectiveness of strategic decision comprehensiveness because they involve different degrees of analyzability and thus different information-processing demands in strategic decision making.

\section{Moderating Effects of Technology and Demand Uncertainties}

Anderson and Tushman suggested that technology uncertainty tends to "create especially hazardous conditions above and beyond any demand unpredictability associated with it" (2001: 685). This statement suggests that although technology and demand uncertainties are related environmental phenomena, managers tend to perceive intrinsic differences in the information-processing requirements they create (Abernathy \& Clark, 1985). Rapid technological changes offer new product opportunities for firms, but such opportunities may get obsolete quickly. Technological information is dense, reflecting a high frequency of unexpected and novel changes that make it difficult for firms to respond with objective and formal procedures (Daft \& Weick, 1984). Such information is also perceived as highly equivocal, meaning that it has multiple and ambiguous underlying meanings and causes that defy specific analysis and uniform interpretation (Daft \& Macintosh, 1981: 211; Weick, 1969). Thus, technology uncertainty increases difficulties and costs for project members in collecting and analyzing not only the nature of technological changes, but also, more importantly, their implications for customer demands and needs (Tushman \& Nelson, 1990). Indeed, the value of customer information acquisition and analysis by firms tends to diminish when technology uncertainty is high because customers tend to have very little knowledge about nascent technologies and their implications for their needs (Jaworski \& Kohli, 1993).

Technology uncertainty also imposes severe limitations on existing firm capabilities because it tends to disrupt the balance between the resource needs of projects and available organizational resources and skills (Tushman \& Nelson, 1990). Such disruption increases the costs and difficulties of information collection, analysis, and integration among decision makers. Not surprisingly, firms tend to respond to technology uncertainty by competing on the basis of technology that does not necessarily reflect customer needs under the assumption that technological superiority is the key to success (Jaworski \& Kohli, 1993).

This discussion suggests that managers perceive technology uncertainty as unanalyzable, a perception that makes organizational responses highly uncertain. In such a situation an incremental, trialand-error decision-making process rather than a comprehensive process is likely to be more effective (Braybrooke \& Lindblom, 1963; Daft \& Weick, 1984: 291). Consequently, we posit that the benefits of strategic comprehensiveness are likely to be min- 
imal in a technologically uncertain environment because comprehensiveness cannot manage the information-processing demands. Viewed largely as a threat to organizational functioning, technology uncertainty reflects time-sensitive and equivocal conditions requiring fast information processing and real-time information flow. Yet strategic decision comprehensiveness is by nature a slow process (Fredrickson, 1984). Also, technology uncertainty has detrimental impacts on organizational competencies in product development. In particular, a good-quality product and successful product development are built on synergies between a firm's accumulated experience with existing product technology, manufacturing process, and customer interfaces as well as effective communication among functions (Wheelwright \& Clark, 1992). However, as Song and Montoya-Weiss (2001: 73) found, technology uncertainty disrupts such synergies. A project team's resources and skills become ineffective, thereby diminishing effective product development activities. Such disruptions are unlikely to enhance effective strategic decision comprehensiveness. For this reason, firms often fail to develop successful new products when technology uncertainty is high because they cannot match their information-processing systems to the new technological challenges (Pavitt, 1998).

In summary, the information processing theory argument is that strategic decision comprehensiveness hurts performance and new product quality in an uncertain environment because a firm faces complex information-processing requirements. We sought to add to this received knowledge by positing that this prediction may hold only in technologically uncertain environments in which information is perceived to be unanalyzable, responses are highly uncertain, and comprehensiveness slows down decision making (Galbraith, 1973) and interferes with real-time information search and analysis. Hence,

Hypothesis 1a. Strategic decision comprehensiveness will have a stronger, negative relationship with new product performance when technology uncertainty is high than when it is low.

Hypothesis 1b. Strategic decision comprehensiveness will have a stronger, negative relationship with new product quality when technology uncertainty is high than when it is low.

In contrast to technology uncertainty, demand uncertainty prompts firms to reach out to customers (Jaworski \& Kohli, 1993). The intensified customer interaction activities enhance a firm's understanding of the uncertainty because customers, particularly lead users, can sometimes articulate their problems and suggest solutions to a firm (Wheelwright \& Clark, 1992). Further, Christensen and Bower (1996) found that changes in customers' demands and preferences rarely deviate substantially from current firm competences and experiences. This stability means that customer information is less equivocal to the firm than technology information and that the causes of demand uncertainty are amenable to specific analysis and interpretation of their meanings for organizational activities. Firms can thus tap emerging customer opportunities without costly investments in new capabilities (Daft \& Macintosh, 1981). Hence, firms are able to compete effectively in uncertain demand environments because they can produce products that address customers' specific needs (Grewal \& Tansuhaj, 2001).

Consequently, unlike technology uncertainty, demand uncertainty is perceived as more analyzable, making it more amenable to formal search and analysis with rules and criteria for interpretation. As Daft and Macintosh (1981: 208) argued, where information is analyzable, managers can follow an objective, computational process to resolve problems, as a correct response can usually be identified. Thus, strategic decision comprehensiveness is a more appropriate process in such an environment because it allows for efficient use of information to identify appropriate responses (Daft \& Weick, 1984: 291). By being comprehensive in such an environment, a project team develops considerable knowledge about how to develop need-satisfying products with superior value (Wheelwright \& Clark, 1992).

In sum, although according to information processing theory strategic decision comprehensiveness may be unsuited for uncertain environments, we have advanced this theory by positing a crucial qualification premised on the higher degree of perceived analyzability of demand uncertainty. That is, because the unpredictability and problems of information search and interpretation are reduced under demand uncertainty, a comprehensive decision process is likely to uncover appropriate solutions to customer needs in order to enhance new product quality and market performance. Hence,

Hypothesis 2a. Strategic decision comprehensiveness will have a stronger, positive relationship with new product performance when demand uncertainty is high than when it is low.

Hypothesis 2b. Strategic decision comprehensiveness will have a stronger, positive relationship with new product quality when demand uncertainty is high than when it is low. 


\section{METHODS}

\section{Study Context and Sample}

The sample frame for the study was new technology ventures located in the industrial parks in Guangdong province in China. China has been remarkably successful in incubating new technology ventures primarily through the establishment of high-technology industrial parks across the country. Over the past decade, China has established 53 national industrial parks, in which over 20,000 technology firms have been incubated; their sales income at the end of 2000 was $\$ 115$ billion. Extant research suggests that China's economic transition poses severe resource and other challenges for new ventures (Li \& Atuahene-Gima, 2001, 2002). Compared with their counterparts in developed economies, new technology ventures in China face higher environmental uncertainty in terms of significant political and economic changes, a less developed institutional framework, and the increasing power of market competition.

Further, new ventures often lack adequate financial and managerial resources and well-established routines for effective strategic decision making. Difficulties in understanding and responding to technology and demand uncertainty tend to arise because new ventures have fewer resources for environmental scanning, fewer individuals to perform information processing, and fewer top managers who are sufficiently removed from operational problems to enable effective strategic assessments free from day-to-day disturbances. Together, these factors suggested that the Chinese new venture context offered a rich setting for examining the contingent effects of strategic decision comprehensiveness on new product performance. The moderating effects of technology and demand uncertainty might perhaps be more pertinent and pronounced in this setting.

We drew a random sample of 1,000 new ventures (eight years old or younger) from a list of 12,000 firms. We contacted the CEO of each firm to solicit participation in the study. We developed the questionnaire using the conventional back-translation process. The questionnaire was then pilot-tested through in-depth group interviews with 16 founding team members of 5 new ventures to determine the face validity, clarity, and relevance of the measures in the Chinese context. We administered the questionnaire on-site. A trained interviewer scheduled appointments, presented key informants with the questionnaire, and answered general questions and collected the completed questionnaire. Each interview lasted an average of two hours.

We asked two or three founding team members who were involved in the specific new product project to deliberate on each questionnaire item and assign a single rating based on consensus. In addition to reflecting the consensus decision making central to Chinese culture, this approach had several other advantages for the current study. First, given the complexity of strategic decision making, having multiple knowledgeable respondents discuss and answer questions guarded against attribution bias and memory lapses about the events associated with the project, and our process should therefore have yielded more valid data than single-respondent ratings or aggregated multiple-respondent ratings. Second, although time consuming, the consensus approach ensured greater cooperation and interest from the sample, thus increasing the participation rate of ventures in the study. We learned that asking multiple respondents to complete the same questionnaire separately was problematic because they viewed such a procedure as implying a lack of trust in their individual responses. Finally, the procedure allowed the respondents to deliberate on the issues and ask for clarifications from the interviewer to gain better understanding of the study. These features tended to guard against retrospective bias in reporting.

The interviewer defined a new product strategic decision as one involving large resource commitments, long time horizons, and decisions that were difficult to reverse in the short term, such as the determination of objectives, target markets, and resource allocation for a new product. The key informants of each company identified and described at least two new products their firm had launched into the market within the last three years. To avoid selection bias, the interviewer then randomly selected one of the new products described as a focus for the interview.

We obtained data from 373 firms, thus achieving a participation rate of 37.3 percent. All key informants were CEOs, managing directors, or senior managers in such areas as engineering and business development. They had average company tenures of 4.6 years and average industry experience of 8.09 years. Eighty-three percent were male, with 28, 58, and 14 percent having secondary education, bachelor's, and postgraduate (master's and Ph.D.) degrees, respectively. Finally, 24 percent of the key informants were below 30 years of age, 56 percent were between 30 and 50 years, and the rest were over 51 years. Of the responding ventures, the average number of founding team members was 5.51 (s.d. $=3.38)$. The average venture age was 4.34 years (s.d. $=2.01)$. On average they had $141 \mathrm{em}-$ ployees (s.d. $=369$ ) and U.S. \$7.6 million in sales. Sixty-three percent were from the electronic infor- 
mation industry (for example, information technology, telecommunications, electronics), and 37 percent were from other industries (for example, pharmaceuticals, biotechnology, new energy and new materials). We compared the respondent firms with nonrespondents on age, number of founding team members, number of employees, and sales data obtained from the sample frame. The two groups were not significantly different.

\section{Measures, Reliability, and Validity}

The measurement of performance of new ventures can be accomplished in two ways. First, the subjective reports of knowledgeable informants can be used. Second, a researcher can use secondary sources or knowledgeable respondents' reports of absolute values of performance, where archival data are unavailable (Chandler \& Hanks, 1993). This latter practice, we argue, is justified on the grounds that archival data (when available) are also reported by knowledgeable informants in firms. In this study, we measured new product performance in two ways. First, we developed a four-item subjective measure for new product performance ( $\alpha=$ .79); responses were rated on a format ranging from 1, "low," to 5, "high." Informants rated a new product's degree of success relative to those of competitors' products on sales growth, market share growth, growth in profit, and return on investment. Subjective performance measures such as those used here have been found useful in prior research on strategic decision comprehensiveness (e.g., Priem et al., 1995).

Second, since archival sources of performance data at the new product level were unavailable, we relied on key informants to provide absolute values for performance (Autio, Sapienza, \& Almeida, 2000; Li \& Atuahene-Gima, 2002). We asked the informants to report the sales growth rate for the new product in each of the last three years and then calculated the average as our measure of performance. Sales growth is widely considered as the key indicator of the market acceptance of a new venture's products (Autio et al., 2000). Sales growth had a positive correlation with the subjective new product performance measure $(r=.28$, $p<.01$ ), indicating the validity of the subjective measure.

We measured new product quality $(\alpha=.81)$ with a five-item scale asking the informants to assess the degree to which they agreed with questions about the new product's quality. A sample item is "The product was perceived by customers as more reliable than competitors' products." The items assessing new product quality and the remaining noncon- trol variables were rated on the same five-point response scale $(1=$ "strongly disagree" to $5=$ "strongly agree"). Strategic decision comprehensiveness $(\alpha=.82)$ was measured with five items adapted from Miller et al. (1998). A sample item is "The new product project members developed many alternative courses of action to achieve intended objectives."

We measured technology uncertainty $(\alpha=.80)$ with a four-item scale tapping the perceived speed and magnitude of change and uncertainty in technology and the variety of new product introductions afforded by changing technology in the industry. The three-item scale measuring demand uncertainty ( $\alpha=.64$ ) reflected the speed of change in customer demand, product preferences and emergence of new customer segments in the industry. Measures for these two constructs were adapted from Jaworski and Kohli (1993). We controlled for government and financial ties of a new venture's top management team because in China they are critical factors that may impact the venture's performance (Li \& Atuahene-Gima, 2001). We measured government ties $(\alpha=.77)$ with three items. An example is "We have invested a lot of resources in building relationships with government officials." Financial ties $(\alpha=.80)$ were measured with a four-item scale; a sample item is "We have developed close connections with officials in financial institutions." The Appendix lists all the measures for these variables.

We also controlled for several variables in testing the hypotheses. Team size was measured as the number of people who had founded a new venture and played significant roles in its product development. Diversity of experience and diversity of age were measured by asking the informants to indicate, on a single five-point scale, the degree to which the founding team included people with experiences in different industries and various age groups, respectively. These variables may reflect the degree of cognitive resources available to a team and thus may be correlated with decision comprehensiveness and could thereby influence strategy making processes and their outcomes (Rajagopolan et al., 1993). We controlled for new product type (1, "radical," and 0, "incremental") as this aspect of a new product has significant impact on its performance. We measured venture size as number of full-time employees. Large ventures may have greater slack available with which to overcome the costs of decision comprehensiveness. Venture ownership was controlled for because independent and corporate-sponsored new ventures may differ in their level of resources for strategic decision making $(0$, "independent venture," and 1 , "corporate- 
sponsored venture"). Industry type was bifurcated and reflected degree of technological sophistication (Li \& Atuahene-Gima, 2001): firms in the electronic information industry (63 percent of the sample) were coded 0 , and all nonelectronic information firms (37 percent of the sample) were coded 1.

To ensure the validity of the data, we assured confidentiality to all informants. We also provided a rich explanation of the usefulness of the project for the informants' organizations and offered them a summary of the results to foster a sense that they would benefit from involvement in the study. We alleviated potential concerns about common method bias in two ways. First, as reported earlier, the sales growth data obtained from a sample of firms correlated significantly with the subjective measures of new product performance. Second, we conducted a Harman's one-factor test in which all the variable measures were entered into a singlefactor analysis. The results showed that neither a single factor nor a general factor accounted for the majority of the covariance in the measures. All the measures "loaded" cleanly on separate factors, with all factor loadings above .40, a common threshold for acceptance. The constructs had high reliability, with all but demand uncertainty having alphas over .70. Composite reliability, assessed with a LISREL-generated estimate of internal consistency analogous to coefficient alpha (Fornell \& Larcker, 1981: 46), provided further evidence of internal consistency. The estimates ranged from .72 to .85 and are included in Table 1.

The results of a confirmatory factor analysis (see the Appendix) indicated that the measurement model fitted the data reasonably well $\left(\chi^{2} / d f=1.92\right.$; $\mathrm{GFI}=.89$; $\mathrm{CFI}=.95 ; \mathrm{NFI}=.90 ; \mathrm{NNFI}=.94$; RMSEA $=.05)$, thereby confirming the unidimensionality of each construct in the model (Anderson \& Gerbing, 1988). Convergent validity is observed when the path coefficients from latent constructs to their corresponding manifest indicators are statistically significant (that is, $t>2.0$; Anderson \& Gerbing, 1988). As shown in the Appendix, all items loaded significantly on their corresponding latent construct, with the lowest $t$-value being 7.99 $(p<.05)$, thereby providing evidence of convergent validity. Discriminant validity is obtained when all pairwise latent-trait correlations of constructs are significantly different from 1 (Anderson \& Gerbing, 1988). Table 1 shows that our construct measures met this requirement. A more stringent criterion of discriminant validity is that across all possible pairs of

TABLE 1

Correlation Matrix and Summary Statistics ${ }^{\mathrm{a}}$

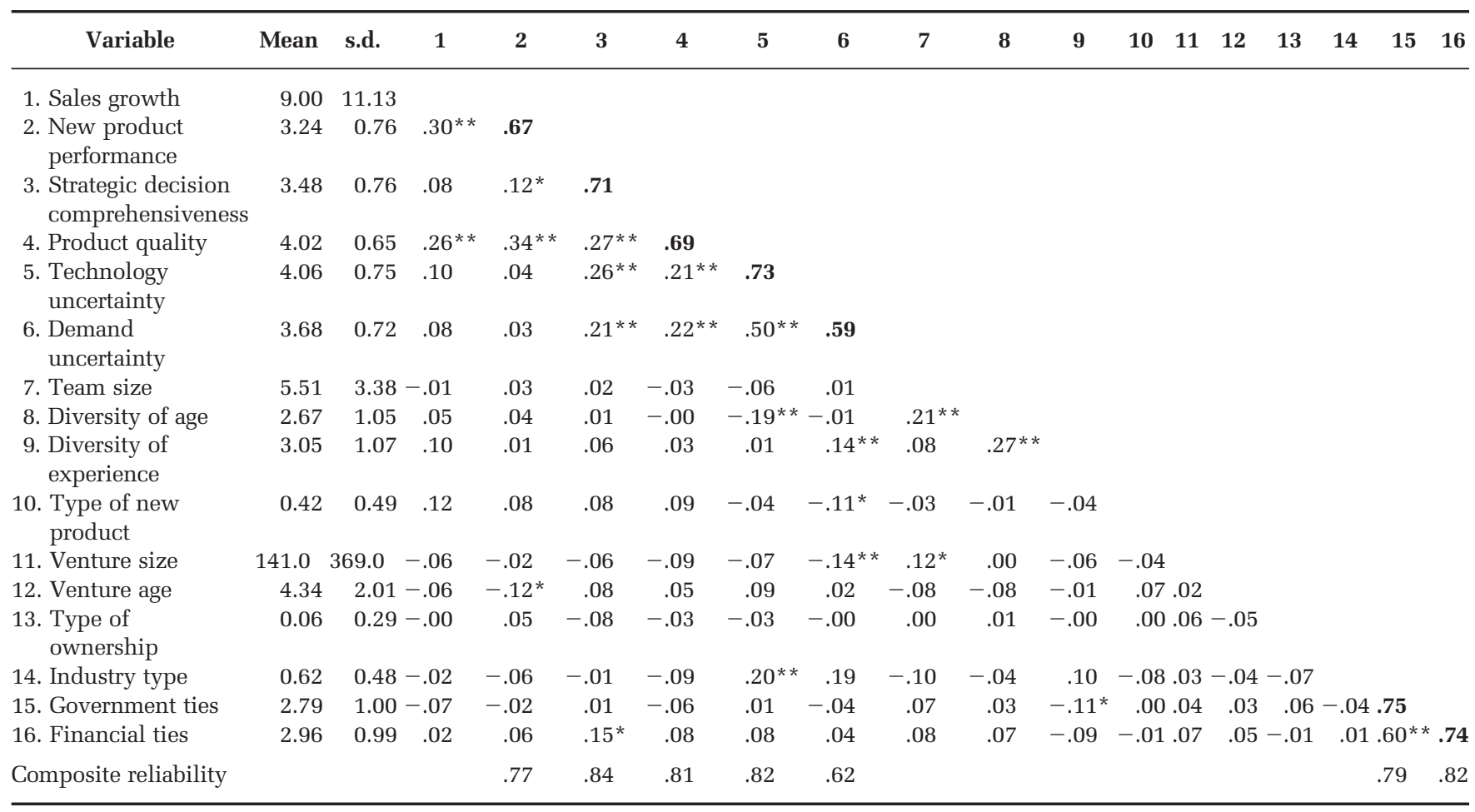

\footnotetext{
${ }^{a} n=260$. Bold figures on the diagonal are the square root of the average variance extracted for the constructs.

${ }^{*} p<.01$

$* * p<.001$
} 
constructs the variance extracted for each construct be greater than the squared latent correlation between a pair of constructs (Fornell \& Larcker, 1981). As shown in Table 1, the diagonal elements representing the square roots of the average variance-extracted values for each of the constructs are greater than the off-diagonal elements, thereby satisfying this discriminant validity criterion (Hulland, 1999). Table 1 presents the descriptive statistics and correlation matrix for the constructs.

\section{RESULTS}

We used moderated regression analysis to test the hypotheses. We mean-centered the independent variables prior to the creation of interaction terms to reduce multicollinearity (Aiken \& West, 1991). The variance inflation factors associated with each of the regression coefficients ranged from 1.04 to 2.26 , suggesting no serious problems with multicollinearity. Table 2 shows the results. We present the results regarding subjective new product performance in models 1 and 2, the results regarding sales growth in models 3 and 4 , and the results regarding new product quality in models 5 and 6 .

The addition of the interaction terms in model 2 added 4 percent $\left(\Delta R^{2}=.04, F=6.38, p<.001\right)$ to the explained variance in subjective new product performance obtained in model 1. Similarly, adding the interaction terms in model 4 contributed 3 percent $\left(\Delta R^{2}=.03, F=4.14, p<.001\right)$ to explained variance in sales growth obtained in model 3 . The effect of the strategic decision comprehensiveness and technology uncertainty interaction term was significant and negatively related to both new product performance $(b=-.29, p<.01)$ and sales

TABLE 2

Results of Contingency Effect of Decision Comprehensiveness on New Product Performance and Quality

\begin{tabular}{|c|c|c|c|c|c|c|}
\hline Variables & Model 1 & Model 2 & Model 3 & Model 4 & Model 5 & Model 6 \\
\hline Constant & $1.61 * * *$ & $1.62 * * *$ & 0.06 & 0.09 & $2.87 * * *$ & $2.86^{* * *}$ \\
\hline Team size & .01 & .01 & -.02 & -.02 & -.02 & -.02 \\
\hline Diversity of age & .02 & .02 & .02 & .03 & .01 & .02 \\
\hline Venture ownership & $.28^{+}$ & $.32 *$ & $.49^{+}$ & $.54^{+}$ & -.17 & -.16 \\
\hline Industry type & -.09 & -.04 & .05 & .13 & $-.24 * *$ & $-.23 * *$ \\
\hline Venture size & -.00 & -.00 & .00 & .00 & -.00 & -.00 \\
\hline New product type & .14 & $.15^{+}$ & $.37^{*}$ & $.39^{*}$ & .12 & .12 \\
\hline Government ties & -.07 & -.07 & -.13 & -.13 & $-.16^{* *}$ & $-.15^{* *}$ \\
\hline Financial ties & $.12^{*}$ & $.11^{*}$ & .10 & .09 & $.12^{*}$ & $.11^{*}$ \\
\hline $\begin{array}{l}\text { Strategic decision } \\
\text { comprehensiveness }\end{array}$ & .06 & .10 & .02 & .06 & $.12^{*}$ & $.11^{*}$ \\
\hline $\begin{array}{l}\text { Strategic decision } \\
\text { comprehensiveness } \\
\times \text { technology }\end{array}$ & & $-.29 * *$ & & $-.39 *$ & & -.02 \\
\hline $\begin{array}{l}\text { uncertainty } \times \\
\text { demand uncertainty }\end{array}$ & & $.21^{*}$ & & $.36^{*}$ & & $.14^{*}$ \\
\hline$R^{2}$ & .18 & .22 & .15 & .18 & .17 & .19 \\
\hline Adjusted $R^{2}$ & .13 & .17 & .10 & .13 & .13 & .14 \\
\hline$F$ & $3.64 * * *$ & $4.13^{* * *}$ & $3.02 * * *$ & $3.23 * * *$ & $4.01 * * *$ & $3.81 * * *$ \\
\hline$\Delta R^{2 \mathrm{~b}}$ & & .04 & & .03 & & .02 \\
\hline$F$ for $\Delta R^{2}$ & & $6.38^{* * *}$ & & $4.14^{* * *}$ & & $2.27^{*}$ \\
\hline
\end{tabular}

${ }^{a}$ Unstandardized regression coefficients are reported.

${ }^{\mathrm{b}}$ With entry of interaction terms.

${ }^{+} p<.10$

${ }^{*} p<.05$

** $p<.01$

$* * * p<.001$ 
growth $(b=-.39, p<.05)$, thus supporting Hypothesis 1a. To plot this interaction effect, we constrained the variables in model 2 except decision comprehensiveness and technology uncertainty to means. Strategic decision comprehensiveness and technology uncertainty took the values of one standard deviation below (a low level) and above (a high level) the mean. The plot is shown in Figure 1. In keeping with Hypothesis 1a, Figure 1 shows a negative relationship between strategic decision comprehensiveness and new product performance when technology uncertainty is high.

Demand uncertainty positively moderated the relationship between strategic decision comprehensiveness and new product performance $(b=.21$, $p<.05)$ and sales growth $(b=.36, p<.05)$, thus supporting Hypothesis 2a. Consistently, the plot of this interaction depicted in Figure 2 shows a positive relationship between strategic decision comprehensiveness and new product performance when demand uncertainty was perceived as high. However, this figure also suggests that strategic decision comprehensiveness diminishes new product performance when demand uncertainty is low.

The moderating effect of technology uncertainty on the relationship between strategic decision comprehensiveness and new product quality was negative but not significant $(b=-.02$, n.s.). Hence, Hypothesis $1 \mathrm{~b}$ was not supported. In contrast, demand uncertainty positively moderated the relationship between strategic decision comprehensiveness and new product quality $(b=.14, p<.05)$, thus supporting Hypothesis 2b. The plot of this interaction, shown in Figure 3, is consistent with Hypothesis $2 \mathrm{~b}$.

Among the control variables, venture age had a significantly negative relationship with both new product performance and sales growth. This finding suggests that younger ventures are more likely to be successful in new product development than older ventures. New product type and product quality were also positively related to both measures of new product performance. Corporate-sponsored ventures appeared to have higher new product performance than privately owned ventures. New product quality was positively related to financial ties, but negatively related to government ties and firm industry.

\section{DISCUSSION}

Previous research has yielded conflicting results on how environmental uncertainty moderates the relationship between strategic decision comprehensiveness and firm performance. In past work, however, researchers have paid insufficient attention to how different sources of environmental uncertainty moderate the impact of strategic decision making processes on performance. We advanced this research stream by attending to the differing moderating effects of two sources of environmental uncertainty in the context of new product decision making. Premised on the insight of information processing theory that managerial interpretations of the information-processing demands from sources of environmental uncertainty differ, our approach explicitly incorporated the different moderating effects of technology and demand uncertainty on the effectiveness of strategic decision comprehensiveness.

The empirical findings support our study's central proposition. Specifically, our results suggest that strategic decision comprehensiveness hurts new product performance when technology uncertainty is higher because it is unsuited to the information-processing requirements in such an environment. Strategic decision comprehensiveness slows down decision making and interferes with real-time information flow in an environment in which information is perceived as unanalyzable and responses as uncertain. In contrast, strategy decision comprehensiveness enhances new prod-

FIGURE 1 Moderating Effect of Technology Uncertainty

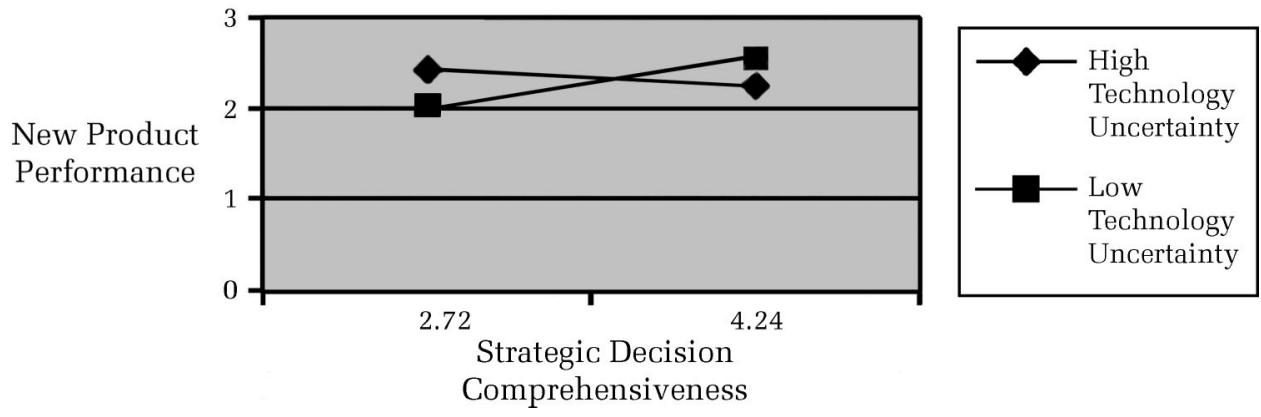


FIGURE 2

Moderating Effect of Demand Uncertainty

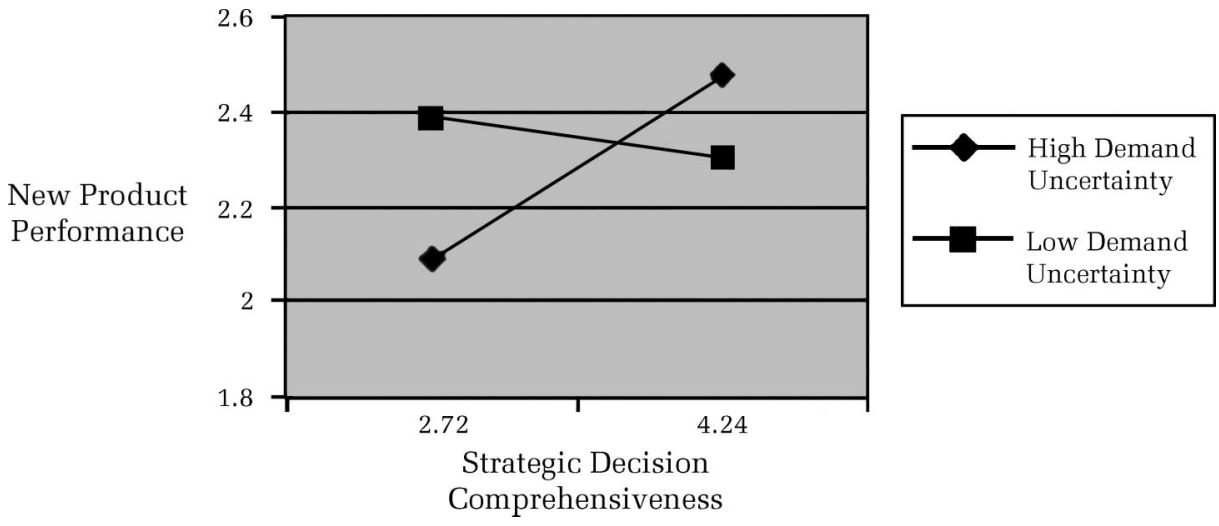

FIGURE 3 Moderating Effect of Demand Uncertainty

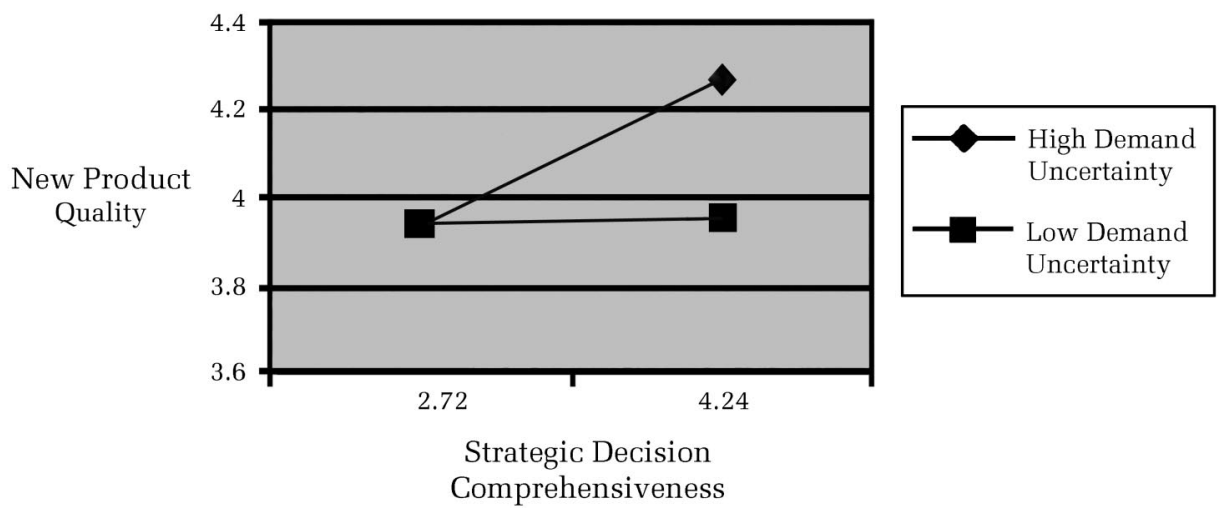

uct quality and performance when demand uncertainty is higher. Because demand uncertainty is perceived as analyzable, it presents less demanding information-processing requirements. Hence, a firm can exploit existing competencies to develop more certain strategic responses to new customer opportunities.

Surprisingly, our results also show that strategic decision comprehensiveness diminishes new product performance when demand uncertainty is lower (see Figure 2). A possible explanation for this result is that low demand uncertainty presents few new opportunities to justify the cost and time required for strategic decision comprehensiveness. It may be more beneficial for a firm to lock into standard modes of responses to customer needs in such a situation. As Galbraith (1973: 15) suggested, where conditions are routine and simple, as is the case when demand uncertainty is low, standard rules and programs are more effective in absorbing the relatively small uncertainty facing an organization. It appears that the elaborate process of strategic decision comprehensiveness may stand in the way of simpler and cheaper ways of decision making when demand uncertainty is low.

Our findings also indicate that in environments of high demand uncertainty, the relationship between strategic decision comprehensiveness and new product performance is replicated when new product quality is considered as an alternative performance outcome. However, in environments in which technology uncertainty is high, strategic decision comprehensiveness has an insignificant relationship with new product quality. It could be that since project members have great difficulties in collecting and analyzing the implications of rapid technological changes, they may have difficulties in understanding how new technology information can be used to develop a good-quality product. Thus, the impact of strategic decision comprehensiveness on product quality becomes less pronounced in such an environment.

Additionally, we note also that product quality showed positive relationships with new product performance as well as with strategic decision comprehensiveness. These findings suggest that new 
product quality may be an outcome variable that intervenes between strategic comprehensiveness and new product performance. Indeed, a key tenet of the synoptic model is that by meeting the requirements of strategic decision comprehensiveness, a project team achieves superior performance because it is able to make more effective decisions and implement higher-quality solutions for problems encountered in the decision-making process (Dean \& Sharfman, 1996; Eisenhardt, 1989). Thus, our results suggest that strategic decision comprehensiveness has a dual impact on performance under conditions of high demand uncertainty via its direct effect and also via its indirect effect by enhancing new product quality.

\section{Theoretical Contributions and Future Research Directions}

The present study makes several important contributions to research examining strategic decision making. A premise of strategic decision making research has been that fit between the informationprocessing capacity offered by a firm's strategy process and the nature of the environmental uncertainty facing the firm is an important determinant of success. A good fit ensures better performance, and a misfit leads to poor performance (Daft \& Macintosh, 1981; Galbraith, 1973). Research in this area has generated important insights. However, as noted earlier, the pattern of results has not always been consistent. The current study extends and enriches researchers' understanding in several ways. First, instead of considering environmental uncertainty as a unidimensional construct and possibly reaching incomplete or contradictory conclusions, as those conducting previous empirical tests have done, we adopted a multidimensional approach. The explicit incorporation of technology and demand sources of environmental uncertainty, although introducing increased complexity into received knowledge on strategic decision comprehensiveness, provides the crucial insight that the sources of environmental uncertainty do matter in how strategic decision comprehensiveness influences product development outcomes. Our approach is an important addition to the literature because it clarifies that it is not environmental uncertainty per se, but the information-processing demands created by different sources of uncertainty, that are likely to induce the moderation observed. Our study therefore provides a valuable reference point for future research on strategic decision making. It does this by grounding the influence of perceived differences in information-processing requirements associated with technology and de- mand uncertainty in an empirical assessment. Future research would benefit from expanding our model to include other sources of environmental uncertainty.

Second, in this study, we developed a common set of rationales to explain the effect of strategic decision comprehensiveness on two product development outcomes: new product quality and performance. The results suggest that technology uncertainty and demand uncertainty not only affect the relationship between strategic decision comprehensiveness and new product performance in different ways, but also play different moderating roles when new product quality is the outcome. Thus, our study highlights that strategic decision comprehensiveness may have different effects on product development outcomes under technology uncertainty conditions and demand uncertainty conditions. This finding underscores the importance of Rajagopalan and colleagues' (1993) argument that an effective model of strategic decision making must address multiple goals simultaneously. In this regard, by explicitly examining both new product quality and performance simultaneously, we were able to uncover the complex but important differences in the links between strategic decision comprehensiveness and product development outcomes. Our study suggests that type of product development outcome should emerge as a significant influence in framing the effectiveness of strategic decision making in future theory development and empirical research.

Third, researchers have argued that strategic decision making in product development is a dynamic capability in which managers pool their various business, functional, and personal resources to make choices that shape the major moves of their firms (Eisenhardt \& Martin, 2000: 1107). In this regard, our results suggest that the value of strategic decision making capability may to some extent be externally determined. Consequently, the approach adopted here is broadly in line with recent arguments in the contingent resource-based view that effective deployment of firms' resources and capabilities is conditioned by external environmental factors (Brush \& Artz, 1999; Priem \& Butler, 2001). Therefore, our distinction between technology and demand uncertainties, based on the perceived differences in information-processing demands, is a valuable addition to this literature. It holds promise for resource-based view research examining how internal resource and capability deployments are influenced differently by different sources of environmental uncertainty.

Fourth, previous research on new product development has typically examined environmental and 
development process factors as antecedents of new product performance (Brown \& Eisenhardt, 1995). Few if any studies have investigated the nature of strategic decision making processes as an antecedent of new product performance. Our study contributes to this research stream by broadening it beyond the more conventional factors to highlight the important role that the strategic decision making process plays in enhancing new product quality and performance.

Finally, although the Chinese setting of our study is a strength, given the lack of prior research in this context, we had no comparison country, culture, or group. Hence, our study deals with within-country, -culture, or -group variance. Consequently, we cannot make a compelling case for a unique "Chinese" effect for these results. However, the different moderating effects of technology and demand uncertainties cannot escape speculation regarding a contextual explanation. The Chinese are collectivists who construe themselves as interdependent with others, avoid conflict, and strive for harmony within a group. The dilemma Chinese project groups face in making comprehensive decisions is that divergent opinions are critical in ensuring the discovery and appropriate evaluation of multiple alternatives as a prelude to forming consensus that enhances decision effectiveness (Propp, 1997: 429). Researchers (e.g., Tushman \& Nelson, 1990) have argued that technology uncertainty is more competence destroying than demand uncertainty, making the former less analyzable. Thus, technology uncertainty is more likely to engender divergent opinions, making the achievement of consensus more problematic and thereby slowing down decision making.

We argue that the tension between the needs for diversity of perspectives and for consensus is more likely to be resolved by Chinese decision-making groups in uncertain demand conditions where information is analyzable and the level of understanding is high (Goll \& Rasheed, 1997). In other words, the respective negative and positive moderating effects of technology and demand uncertainties found in this study may reflect differences in the ability of groups in a collectivist culture to achieve consensus and decision effectiveness under the two divergent environmental conditions. A useful direction for future research would be to test these arguments in data on new ventures in different country or cultural settings.

\section{Managerial Implications and Limitations}

The results of this study provide evidence suggesting that managers should pay special atten- tion to the information requirements in an environment when deploying a comprehensive strategic decision making process during new product development. Managers are cautioned that simply distinguishing between certain and uncertain environmental conditions without considering the sources of the uncertainty may hide critical insights into the strategic decision making processes and may hinder the effectiveness of managerial decisions and new product outcomes. We showed that strategic decision comprehensiveness may affect ultimate new product performance and product quality under the appropriate technology and demand conditions. This observation implies that managers should consider how strategic decision making processes affect these multiple outcomes when they set objectives and targets for project teams, and when they reward these teams.

Like any investigation, ours has limitations. Self-reported data pose such potential problems as limited recall by respondents. However, we do not believe recall lapses were a significant problem in this study because we took measures to improve the reliability and validity of retrospective reporting, particularly by gathering consensus ratings from multiple knowledgeable informants. Another possible shortcoming of the study was common method bias. However, we believe that our findings are not an artifact of common method bias because our post hoc examination with the one-factor test indicated no serious common method problems. We also obtained similar empirical results when using more objective measure of new product performance. Finally, all our findings pertain to interaction effects. Common method bias is unlikely to result in significant interaction effects or distort those effects (Brockner, Siegel, Tyler, \& Martin, 1997).

Although we adapted our measures of demand uncertainty from past research (Jaworski \& Kohli, 1993), the reliability of this construct was .64, below the common threshold of .70. Therefore, related findings should be interpreted with some caution. One possible reason for the low reliability is that in an economic transition, demand uncertainty may have unusual dimensions, given the complexity of the transitional market environment (Li \& Atuahene-Gima, 2001). However, methodologists have argued that routine rejection of alphas below .70 may be unwise (Cortina, 1993; Smith, 1996), if the measures being assessed have desirable characteristics such as meaningful coverage of content and reasonable unidimensionality, which is shown by our measures of demand uncertainty. 


\section{Conclusion}

Although strategic decision comprehensiveness is viewed as an important strategy characteristic affecting firm performance, researchers' understanding of its relationship with firm performance is very limited, given the mixed findings in previous literature. Premised on the information processing theory argument that differences in the degree of information's analyzability affect the appropriateness and thus the effectiveness of strategic decision making, we posited and found that the relationships between strategic decision comprehensiveness and new product quality and performance were differently moderated by technology and demand uncertainties. Unlike previous empirical tests, our study therefore highlights the crucial importance of explicitly distinguishing the moderating roles of different sources of environmental uncertainty when examining the performance effects of strategic decision making. Given the potential importance of the conceptual approach developed and tested in this study, we believe that future theoretical development and empirical studies that take this approach are likely to be fruitful in unpacking the complexity of the role of strategic decision making in product development performance.

\section{REFERENCES}

Abernathy, W. J., \& Clark, K. B. 1985. Innovation: Mapping the winds of creative destruction. Research Policy, 14: 3-22.

Aiken, L. S., \& West, S. G. 1991. Multiple regression: Testing and interpreting interactions. Newbury Park, CA: Sage.

Anderson, J. C., \& Gerbing, D. W. 1988. Structural equation modeling in practice: A review and recommended two-step approach. Psychological Bulletin, 103: 411-423.

Anderson, P., \& Tushman, M. L. 2001. Organizational environments and industry exit: The effects of uncertainty, munificence and complexity. Industrial and Corporate Change, 10: 675-711.

Autio, E., Sapienza, H. J., \& Almeida, J. G. 2000. Effects of age of entry, knowledge intensity, and imitability on international growth. Academy of Management Journal, 43: 909-924.

Bourgeois, L. J., \& Eisenhardt, K. M. 1988. Strategic decision processes in high velocity environments: Four cases in the microcomputer industry. Management Science, 34: 816-835.

Braybrooke, D., \& Lindblom, C. 1963. A strategy of decision. New York: Free Press.

Brockner, J. P., Siegel, J. P., Tyler, D. T., \& Martin, C.
1997. When trust matters: The moderating effect of outcome favorability. Administrative Science Quarterly, 42: 558-583.

Brown, S. L., \& Eisenhardt, K. M. 1995. Product development: Past research, present findings, and future research. Academy of Management Review, 20: 343-378.

Brush, T. H., \& Artz, K. W. 1999. Toward a contingent resource-based theory: The impact of information asymmetry on the value of capabilities in veterinary medicine. Strategic Management Journal, 20: 223250.

Chandler, G. N., \& Hanks, S. H. 1993. Measuring the performance of emerging business: A validation study. Journal of Business Venturing, 8: 391-408.

Christensen, C. M., \& Bower, J. L. 1996. Customer power, strategic investment, and the failure of leading firms. Strategic Management Journal, 17: 197-218.

Cortina, J. M. 1993. What is coefficient alpha? An examination of theory and applications. Journal of Applied Psychology, 78: 98-104.

Daft, R. L., \& Macintosh, N. B. 1981. A tentative exploration into the amount and equivocality of information processing in organizational work units. Administrative Science Quarterly, 26: 207-224.

Daft, R. L., \& Weick, K. E. 1984. Toward a model of organizations as interpretation systems. Academy of Management Review, 9: 284-295.

Dean, J. W., \& Sharfman, M. P. 1996. Does decision process matter? A study of strategic decision making effectiveness. Academy of Management Journal, 39: 368-396.

Eisenhardt, K. M. 1989. Making fast strategic decisions in high-velocity environments. Academy of Management Journal, 32: 543-576.

Eisenhardt, K. M., \& Martin, J. A. 2000. Dynamic capabilities: What are they? Strategic Management Journal, 21: 1105-1121.

Fornell, C., \& Larcker, D. F. 1981. Evaluating structural equation models with unobservable variables and measurement error. Journal of Marketing Research, 18: $39-50$.

Fredrickson, J. W. 1984. The comprehensiveness of strategic decision processes: Extension, observations, future directions. Academy of Management Journal, 27: 445-466.

Fredrickson, J. W., \& Mitchell, T. R. 1984. Strategic decision processes: Comprehensiveness and performance in an industry with an unstable environment. Academy of Management Journal, 27: 399-423.

Galbraith, J. R. 1973. Designing complex organizations. Reading, MA. Addison-Wesley.

Goll, I., \& Rasheed, A. M. A. 1997. Rational decisionmaking and firm performance: The moderating role 
of environment. Strategic Management Journal, 18: 583-591.

Grewal, R., \& Tansuhaj, P. 2001. Building organizational capabilities for managing economic crisis: The role of market orientation and strategic flexibility. Journal of Marketing, 65: 67-80.

Hough, J. R., \& White, M. A. 2003. Environmental dynamism and strategic decision-making rationality: An examination at the decision level. Strategic Management Journal, 24: 481-489.

Hulland, J. 1999. Use of partial least squares (PLS) in strategic management research: A review of four recent studies. Strategic Management Journal, 20: 195-202.

Jaworski, B. J., \& Kohli, A. K. 1993. Market orientation: Antecedents and consequences. Journal of Marketing, 57(3): 53-70.

Li, H., \& Atuahene-Gima, K. 2001. Product innovation strategy and performance of new technology ventures in China. Academy of Management Journal, 44: 1123-1134.

Li, H., \& Atuahene-Gima, K. 2002. The adoption of agency business activity, product innovation and performance in Chinese technology ventures. Strategic Management Journal, 23: 469-490.

Lindblom, C. 1959. The science of "muddling through." Public Administration Review, 19(2): 79-88.

Miller, C. C., Burke, L., \& Glick, W. H. 1998. Cognitive diversity among upper-echelon executives: Implications for strategic decision processes. Strategic Management Journal, 19: 39-58.

Pavitt, K. 1998. Technologies, products and organization in the innovating firm: What Adam Smith tells us and Joseph Schumpeter doesn't. Industrial and Corporate Change, 7: 433-452.

Priem, R. L., \& Butler, J. E. 2001. Is the resource-based "view" a useful perspective for strategic management research? Academy of Management Review, 26: $22-40$.

Priem, R. L., Rasheed, A. M., \& Kotulic, A. G. 1995. Rationality in strategic decision processes, environment dynamism, and performance. Journal of Management, 21: 913-929.

Propp, K. M., 1997. Information utilization in small group decision making: A study of the evaluative interaction model. Small Group Research, 28: 424-453.

Quinn, J. B. 1980. Strategies for change: Logical incrementalism. Homewood, IL: Irwin.

Rajagopalan, N., Rasheed, A. M., \& Datta, D. K. 1993.
Strategic decision processes: Critical review and future directions. Journal of Management, 19: 349384.

Smith, N. 1996. Uses and abuses of coefficient alpha. Psychological Assessment, 8: 350-353.

Sniezek, J. A. 1992. Groups under uncertainty: An examination of confidence in decision-making. Organizational Behavior and Human Decision Processes, 52: 124-155.

Song, M., \& Montoya-Weiss, M. M. 2001. The effect of perceived technological uncertainty on Japanese new product development. Academy of Management Journal, 44: 61-80.

Tushman, M. L., \& Nadler, D. A. 1978. Information processing as an integrating concept in organizational design. Academy of Management Review, 3: 613-624.

Tushman, M. L., \& Nelson, R. R. 1990. Introduction: Technology, organizations and innovation. Administrative Science Quarterly, 35: 1-8.

Weick, K. 1969. The social psychology of organizing. Reading, MA: Addison-Wesley.

Wheelwright, S. C., \& Clark, K. B. 1992. Revolutionalizing product development. New York: Free Press.

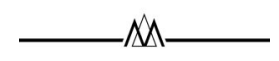

Kwaku Atuahene-Gima (mgkwaku@cityu.edu.hk) is a professor of innovation management and marketing, the director of the Center for Innovation Management and Organizational Change, and the former chair of the Department of Management, City University of Hong Kong. He received his Ph.D. in innovation management and marketing from the University of Wollongong, Australia. His research interests include new product development and management, strategy making in product development, and the intersection of innovation strategy, market orientation, and entrepreneurship, particularly in entrepreneurial technology ventures in emerging economies.

Haiyang Li (hli@cgsb.tamu.edu) is an assistant professor of innovation and strategic management at the Department of Management, Mays Business School, Texas A\&M University. He received his Ph.D. in innovation and strategic management from the City University of Hong Kong. His current research interests include product innovation, entrepreneurship, and the business strategies of new technology ventures in transition economies. 


\section{APPENDIX}

\section{Results of Confirmatory Factor Analysis of Measures ${ }^{\mathrm{a}}$}

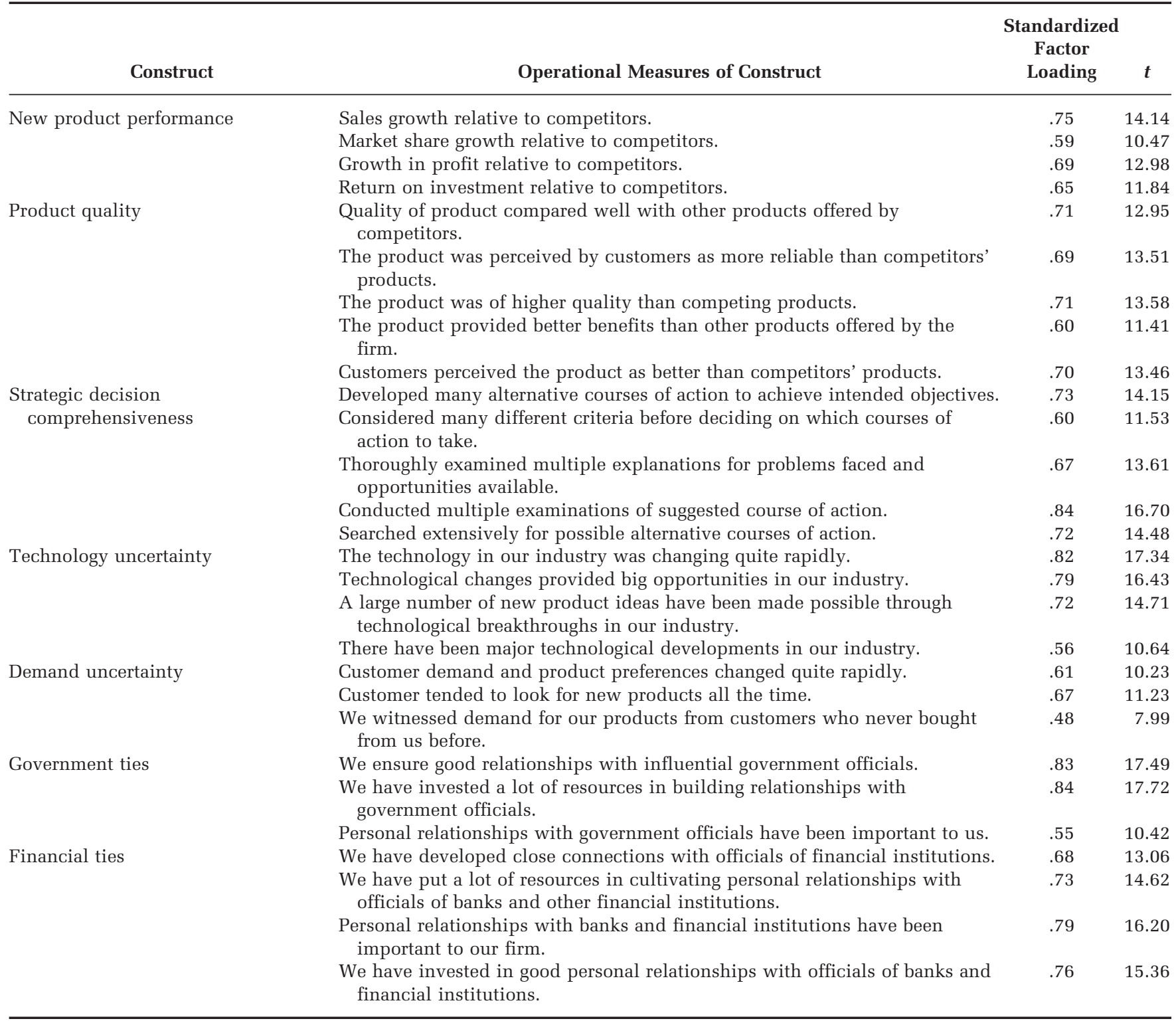

${ }^{\text {a }}$ Model fit indexes: $\chi^{2} / d f=1.92 ;$ RMSEA $=.05 ; \mathrm{GFI}=.89 ; \mathrm{NFI}=90 ; \mathrm{NNFI}=.94 ; \mathrm{CFI}=.95$ 
Copyright of Academy of Management Journal is the property of Academy of Management and its content may not be copied or emailed to multiple sites or posted to a listserv without the copyright holder's express written permission. However, users may print, download, or email articles for individual use. 